\title{
Application of Prefabricated Curtain Wall Sectors in Special-shaped Stadium Projects
}

\author{
Xiong Wei, Gong Wang, Liu Chang, Ma Yong \\ Text/China Construction Shenzhen Decoration Co., Ltd, Shenzhen, China \\ Email address: \\ xiongwei8060606@163.com (Xiong Wei), gongwang@126.com (Gong Wang),863151263@qq.com (Liu Chang), \\ 122716315@qq.com (Ma Yong)
}

\section{To cite this article:}

Xiong Wei, Gong Wang, Liu Chang, Ma Yong. Application of Prefabricated Curtain Wall Sectors in Special-shaped Stadium Projects. Engineering and Applied Sciences. Vol. 5, No. 6, 2020, pp. 119-132. doi: 10.11648/j.eas.20200506.14

Received: October 21, 2020; Accepted: November 21, 2020; Published: December 22, 2020

\begin{abstract}
Due to complex shape and irregularity, projects of special-shaped buildings and venues are always limited by low construction efficiency and uncontrollable quality. The main form of the Application of Curtain Wall Prefabrication Scheme in Phoenix Mountain Sports Center is perforated aluminum panel curtain wall, which connects the stadium and gym through gradually varied curves, and creates the varied facade texture through metal panels of two colors (dark and light). The facade of the perforated aluminum panel curtain wall is streamlined, the overall shape is complex, with gradually varied and irregular shapes in horizontal and vertical directions, the aluminum panels are arranged in staggered seams, and the theoretical positions of the four corners are not coplanar. The number of aluminum panels is about 6000 , and the number of assembled aluminum panels with different size is about 60,000. Conventional construction measures cannot meet the requirements of construction period and benefit. This paper aims to explore the application of prefabrication schemes in special-shaped curtain walls and provide relevant experience for other similar projects by studying the process of implementing the curtain wall prefabrication scheme in Phoenix Mountain Sports Center. A series of practices have proven that a large stadium can be constructed according to the integral hoisting scheme of sectors. Studies on how to design overall hoisting system for steel joist of large volume unit, how to install the steel joist of large volume unit, how to install non-coplanar special-shaped curtain wall and how to implement integral hoisting of metal roofing purlin may help to solve difficulties such as difficult construction, high cost and uncontrollable quality of large volume non-coplanar special-shaped curtain wall. Especially, studies on prefabrication construction techniques may help to simplify complex traditional bulk construction procedures, save time, improve work efficiency and reduce construction costs.
\end{abstract}

Keywords: Special-shaped Curtain Wall, Prefabrication Scheme, BIM Application

\section{Project Overview}

The façade curtain walls are overlapped and staggered, and the color texture and texture size of the metal skin gradually change with the streamline modeling of the façade. Phoenix Mountain Sports Center, a landmark composed of a stadium and a gymnasium and located in Beixing Avenue, North of Chengdu, is under construction in full swing, which may accommodate 60,000 spectators.

Beixing Avenue to the west, Tianlong Road to the north, Tiange Road to the south, and Urban Green Park to the east, Phoenix Mountain Sports Center is located in Dujianian Area, Jinniu District, $4 \mathrm{~km}$ away from Third Ring and $1 \mathrm{~km}$ away from belt freeway, and it is an important node on the
North-South Axis of urban development of Xincheng in Northern Chengdu.

As required by the municipal party committee and municipal government, Phoenix Mountain Sports Center completed will undertake international first-class competitions and domestic first-class leagues to realize goals of professional soccer training for juniors, sports exchanges, exhibition expo, commercial performances, large-scale variety shows, and tourism, aiming to serve as an international first-class competition center, sports professional training center, sports culture exchange center, and sports industry development center, and striving to become a world-class professional stadium. 


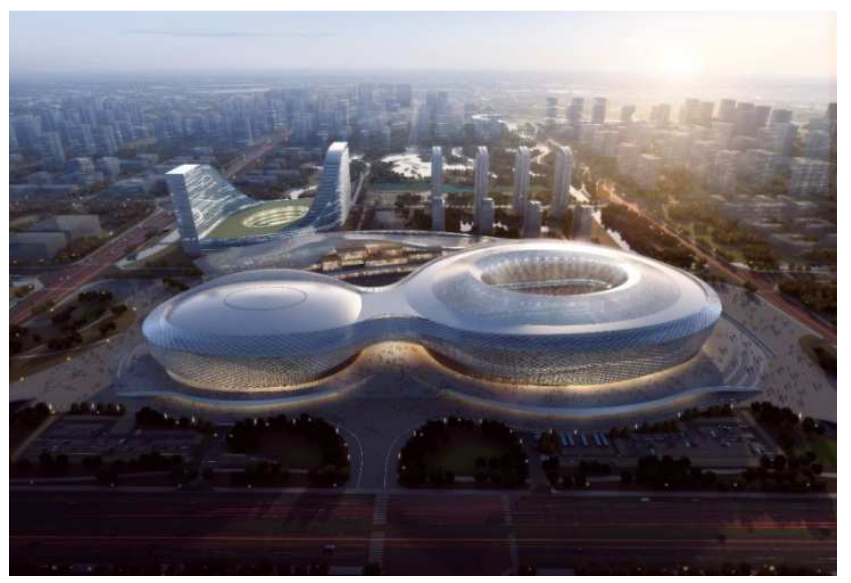

Figure 1. The architectural effect of the project.

Phoenix Mountain Sports Center covers a floor area of about $456,000 \mathrm{~m}^{2}$ (including about $322,000 \mathrm{~m}^{2}$ of venue, about $13,000 \mathrm{~m}^{2}$ of supporting R1 green space, and about $121,000 \mathrm{~m}^{2}$ of facilities for venue). Stadiums are divided into 60,000 professional football stadiums and 18,000 multi-purpose stadiums. The original design organization was China Southwest Architectural Design and Research Institute, and our company participated in the construction as the detailed design and construction organization.

\section{Distribution of Curtain Wall System}

Metal roofing system: Metal roofing is a standing seam interlock system made of aluminum-magnesium-manganese alloy. With the metal material used as roofing layers, the roofing system that is built by reasonably combining the roofing layers that meet the functional requirements of the building by means of modern roofing construction equipment and holding-on of interfaces between roof panels can partially meet the structural support, sound absorption, noise reduction, heat insulation, heat preservation, ventilation, moisture-proof, waterproofing, drainage and interior and exterior decoration functions of the building's roof as required, and the functions of lighting, fire fighting, smoke exhaust, and lightning protection in combination with other building accessories.

Perforated aluminum panel curtain wall system: The main form of its architecture is perforated aluminum panel curtain wall, which connects the stadium and gym through smooth and graceful curves and creates the soft and varied facade texture through metal panels of two colors (dark and light), aiming to create an elegant picture of Sichuan Brocade.

Aluminum grille curtain wall system: Located above a $7 \mathrm{~m}$ platform, it expresses the architectural language through the transition and transformation of perforated aluminum panels

Imitation stone aluminum panel curtain wall system: Located at the periphery of the 7-meter platform area, it connects with the grille ceiling

Glass curtain wall system: Located on the first floor of the commercial area, inside VIP boxes and other areas

Aluminum panel curtain wall system: Located on the first floor and basement area

Aluminum grille ceiling, etc.: Located on the first floor, it connects with the aluminum panel curtain wall

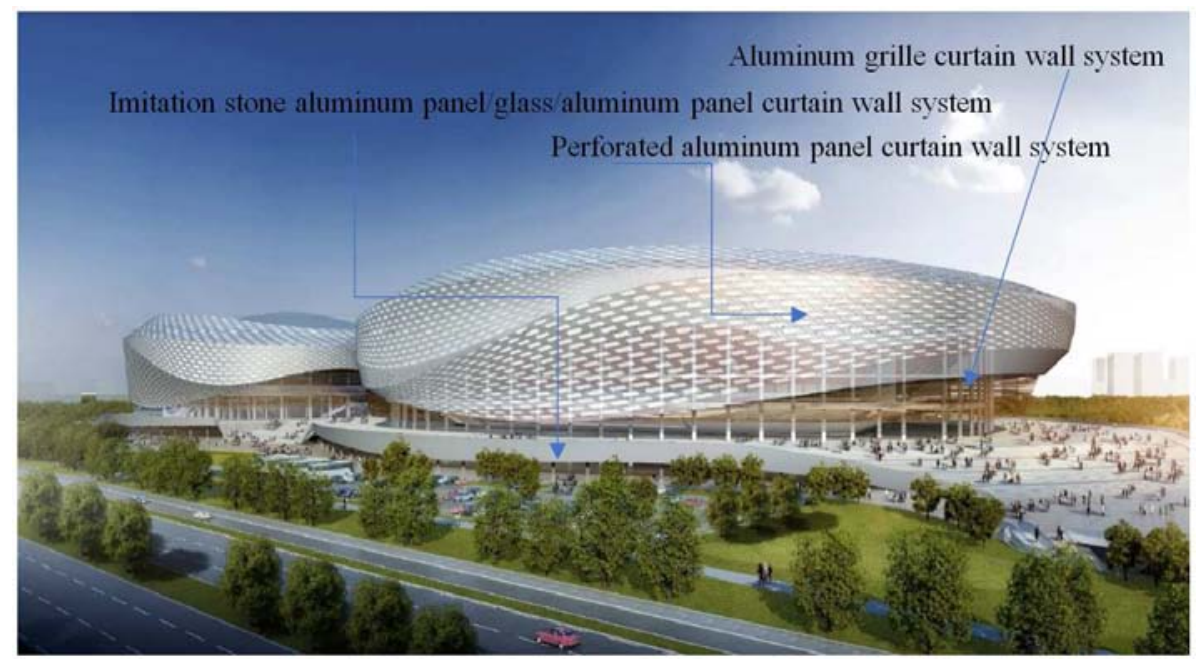

Figure 2. Distribution of curtain wall system.

\section{Analysis of Difficulties in Open Aluminum Panel Curtain Wall}

The main form of the Project is perforated aluminum panel curtain wall, which connects the stadium and gym through gradually varied curves, and creates the varied facade texture through metal panels of two colors (dark and light) [1]. The facade of the perforated aluminum panel curtain wall is streamlined, the overall shape is complex, with gradually varied and irregular shapes in horizontal and vertical directions, the aluminum panels are arranged in staggered seams, and the theoretical positions of the four corners are not coplanar. The number of aluminum panels is about 6000 , and the number of assembled aluminum panels with different size is about 60,000 . Conventional construction measures cannot meet the requirements of construction period and benefit. 


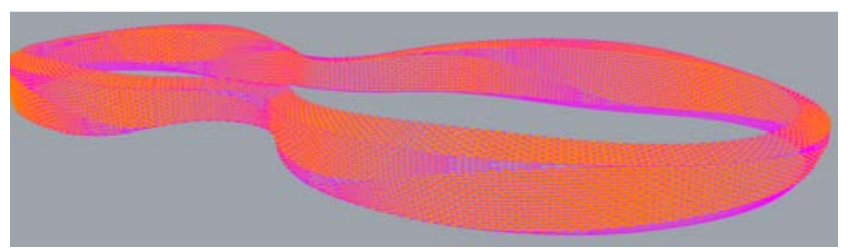

Figure 3. Skin surface model of curtain wall.

Our company conducted a panel analysis on the skin model provided by the Design Institute, and found that the deformation of panels is also irregularly distributed on the façade and that the warpage value varies, making them hard to be systematically classified.

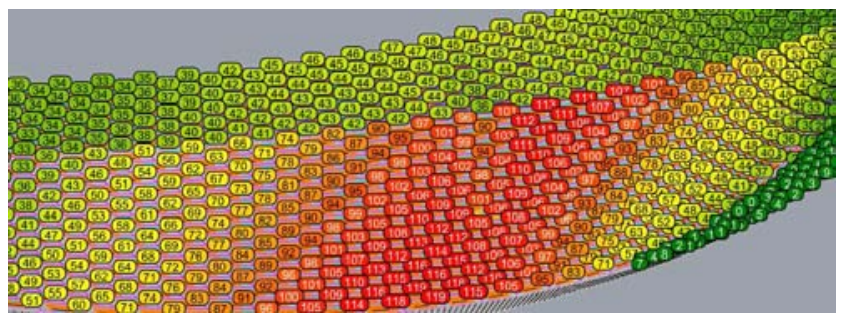

Figure 4. Numbering curtain walls.

Each frame of the steel joist of the curtain wall needs to be positioned separately. The layout of the joist is complicated. In addition to the main steel structure, the steel joist and aluminum joist of the curtain wall are arranged in a staggered manner. The unloading deviation of the main steel structure is unknown, and the space positioning of the curtain wall is complicated.

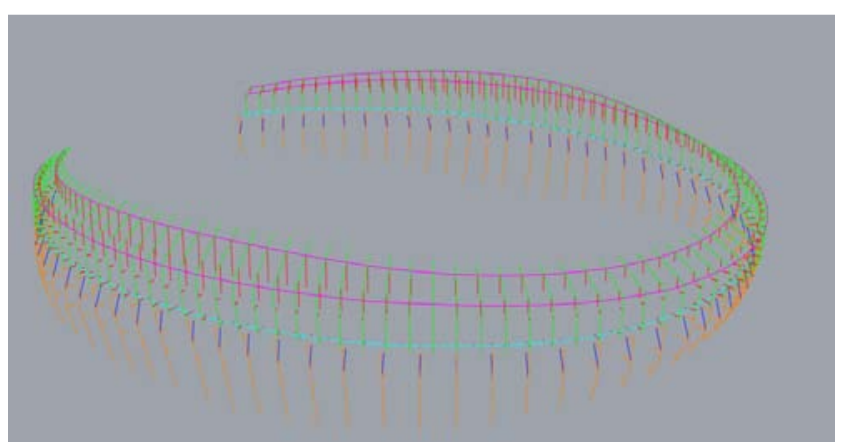

Figure 5. Distribution position of curtain wall steel keels.

The perforated aluminum panel curtain wall adopts open design. The overall sector is divided into horizontal parallelograms [2]. The maximum grid size is about $1.8 \mathrm{mX} 6.0 \mathrm{~m}$. It is divided into internal and external parts to ensure the building facade effect (the maximum size is about $1.4 \mathrm{X} 4.2$ ), and the outer ring is made of densely spliced $3 \mathrm{~mm}$ thick perforated aluminum panels.

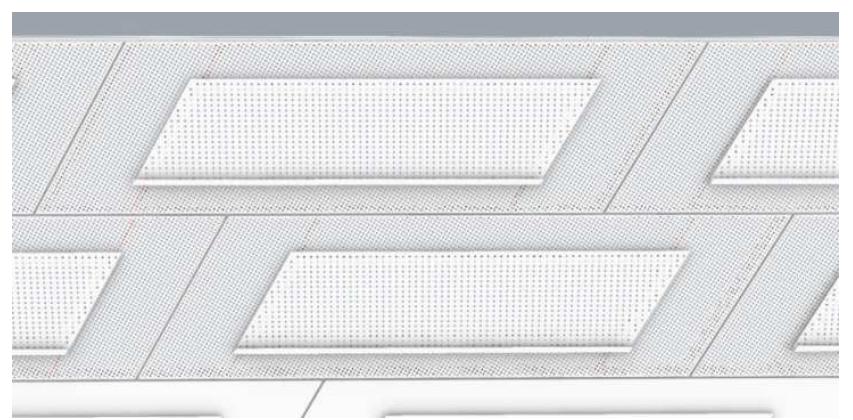

Figure 6. Plate division of perforated aluminum plates.

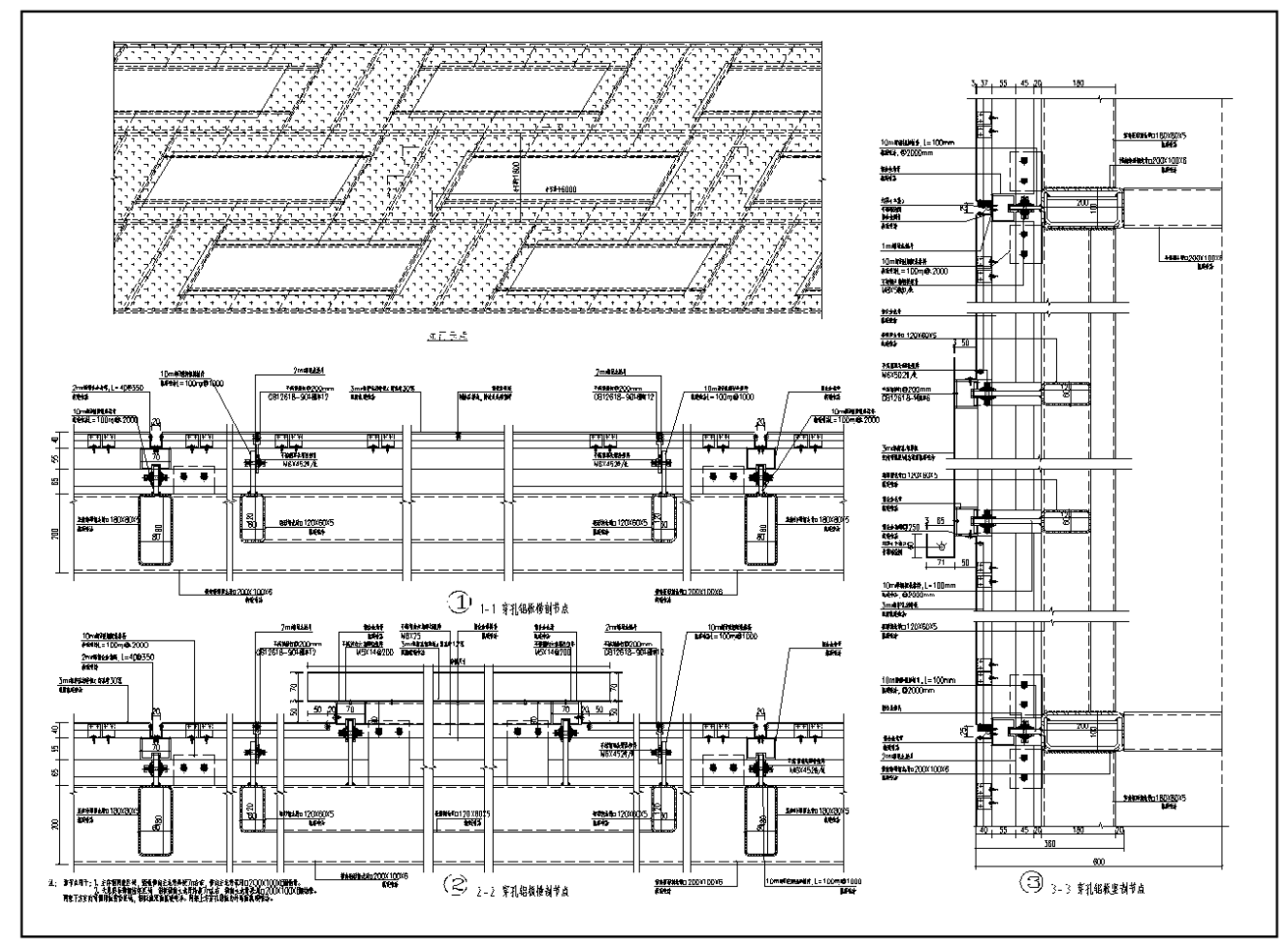

Figure 7. Original Detailed Design Drawing. 


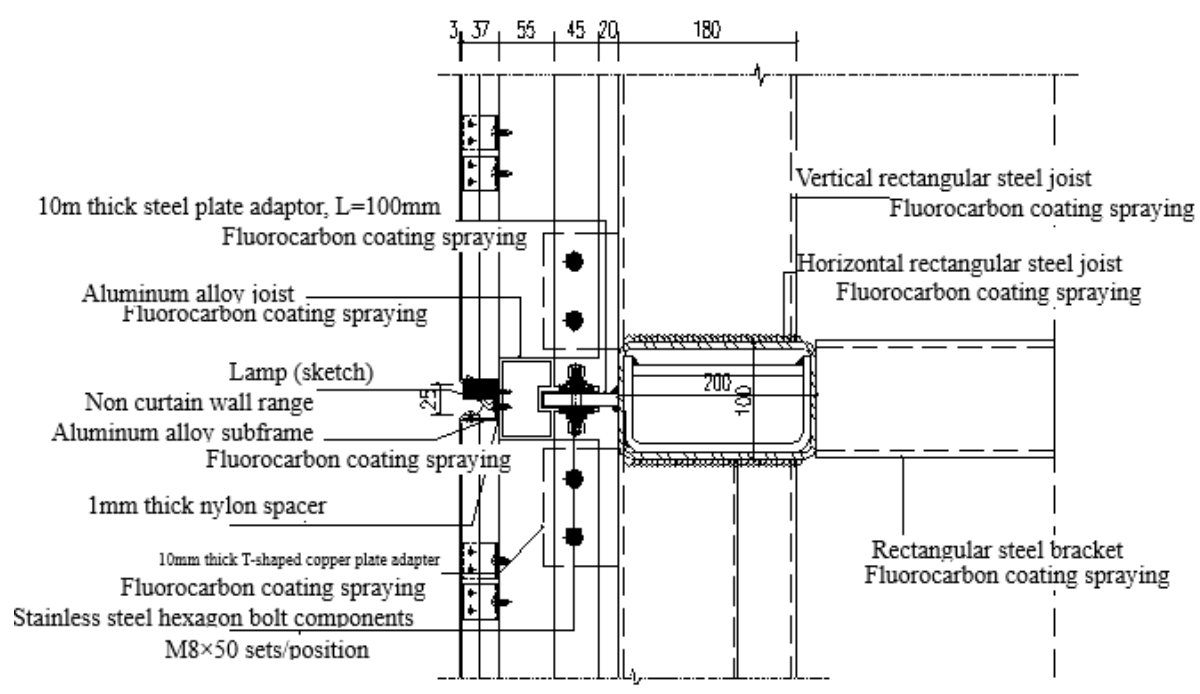

Figure 8. Original design vertical section node 1.

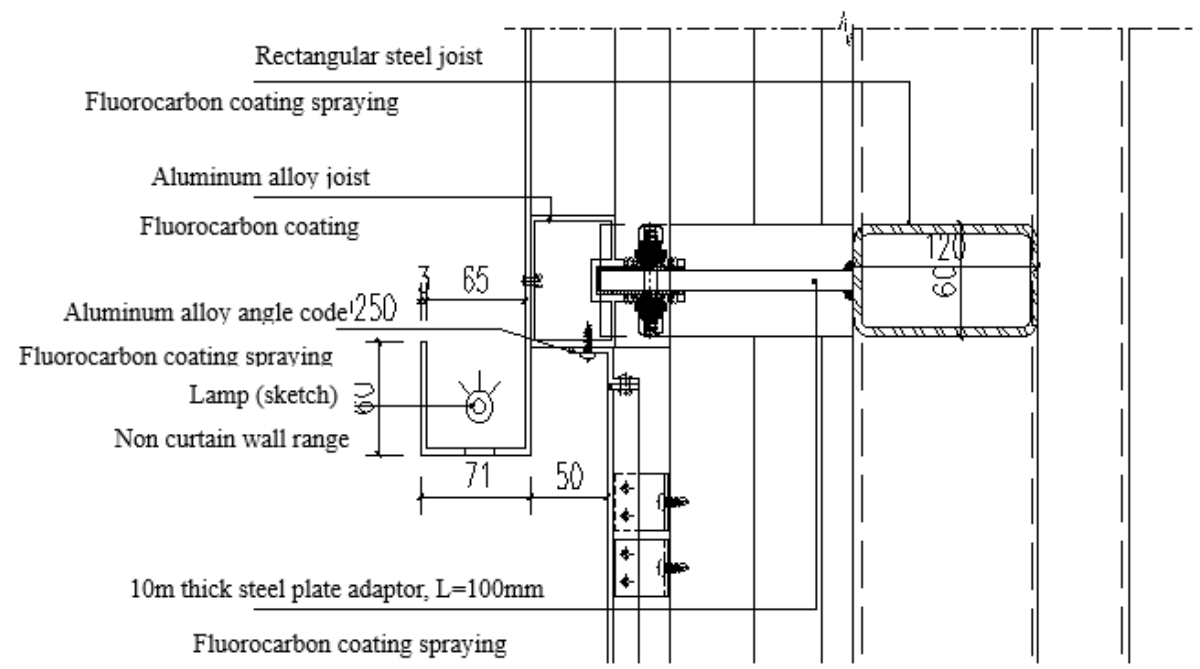

Figure 9. Original design vertical section node 2 .

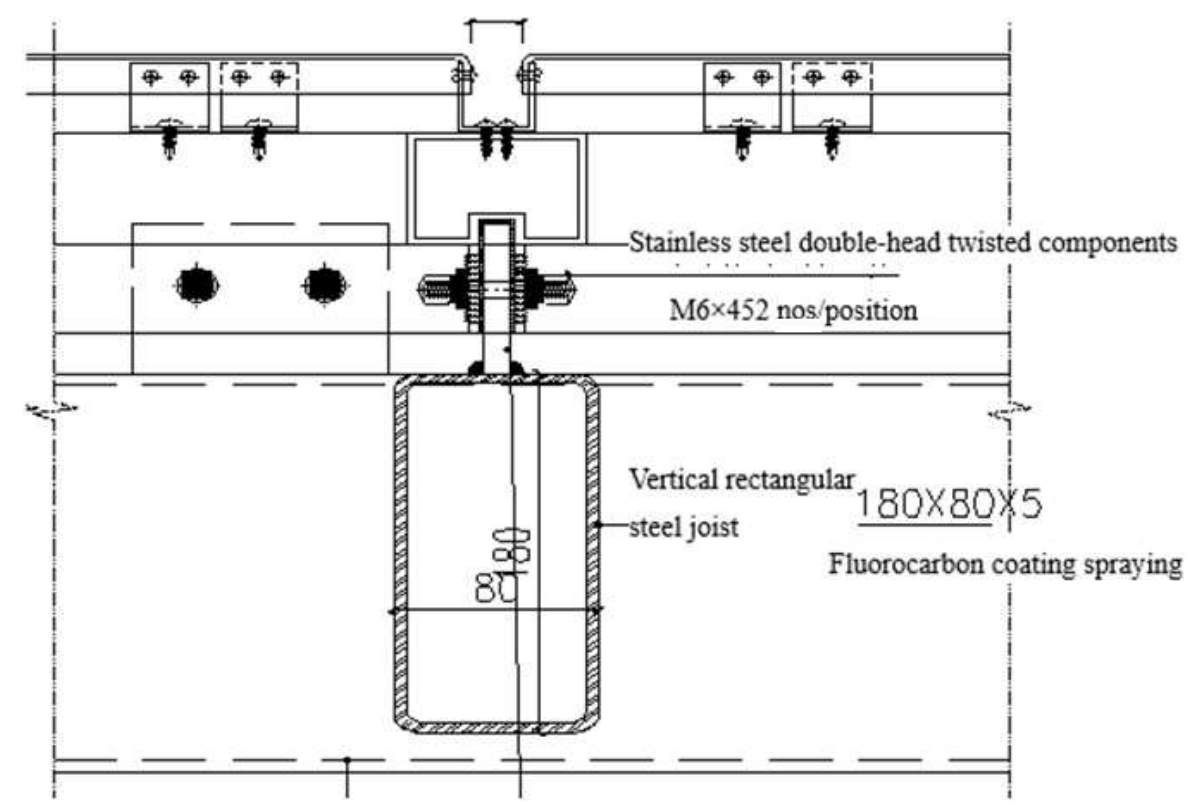

Figure 10. Original design cross section node 1. 


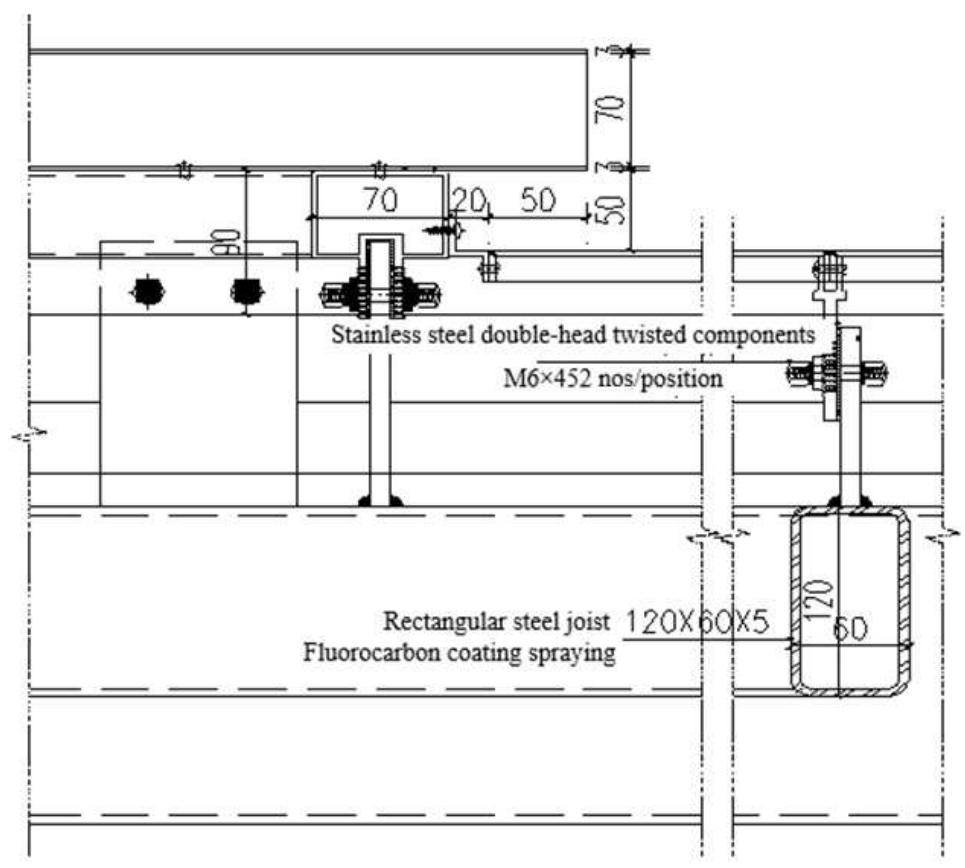

Figure 11. Original design cross section node 2.

According to the detailed drawing and node structure, we can analyze that the shape of the perforated aluminum panels on the facade can be roughly divided into several sectors according to the combination of densely spliced aluminum panels. However, due to the complex structure of the curtain wall system, most of the work needs to be completed on site [3]. In the case of tight construction period, it will bring great difficulties to construction. Another almost insurmountable is on-site positioning. According to the original design vertical section node 1 , there are as many as 5 positions for the upper and lower connection of the plates, and processing errors and on-site deviations are not counted. Theoretically, the number of positioning points reaches more than 400,000 through preliminary statistics.

\section{Analysis of Prefabrication Scheme of Aluminum Panel Curtain Wall}

In order to effectively solve project difficulties, improve on-site work efficiency, and reduce construction cost, our company divided the whole football pitch panel area into 5500 sectors according to the idea of integral hoisting, and divided the overall model by software. The simulated deformation was taken as the basis of scheme design, and the difficulties were solved one by one:

\subsection{Excessive Positioning Points}

The problem of too many positioning points is the top 1 difficulty requiring to be overcome at the beginning of scheme implementation. It will be almost impossible to implement the project within the limited construction period if such a problem fails to be solved.

In order to solve this problem, we need to analyze it by layers. At the connection of steel frame at rear of perforated aluminum panels and the main steel structure, the supporting point cannot be positioned theoretically due to deviation of steel structure, but its spatial position can be locked with reference to its own steel frame, so as to create beneficial conditions for installation of sectors of perforated aluminum panels. Based on this idea, it is only necessary to determine the position of vertical joist while deviation is absorbed (see Figure 12). The horizontal frame is connected to the bracket of vertical joist (see Figure 13). It is also feasible to carry out theoretical positioning and assembly in factory [4].

Our company conducted installation simulation of vertical steel frame on the original steel structure model, and split it for consideration of integral hoisting (see Figures 14 and 15). Positioning of adaptors for hooking sectors on the horizontal frame is also carried out in factory. Processing is performed separately according to different areas and number of vertical frames, while welding and installation are performed on the site based on the numbered layout (see Figures 16 and 17) without extra positioning but only with local review.

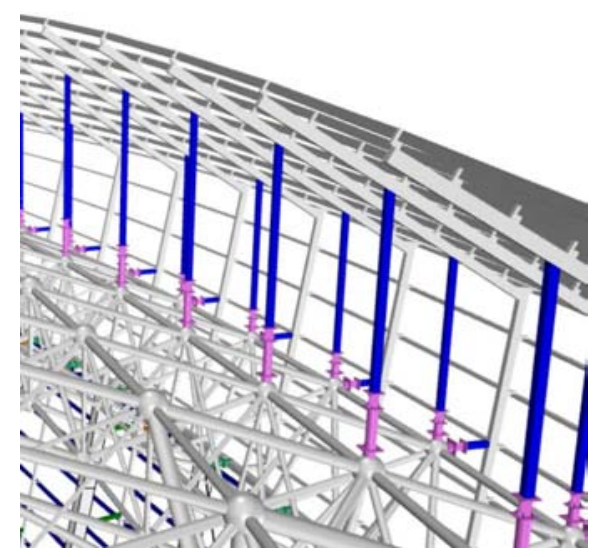

Figure 12. Positioning of vertical keel. 


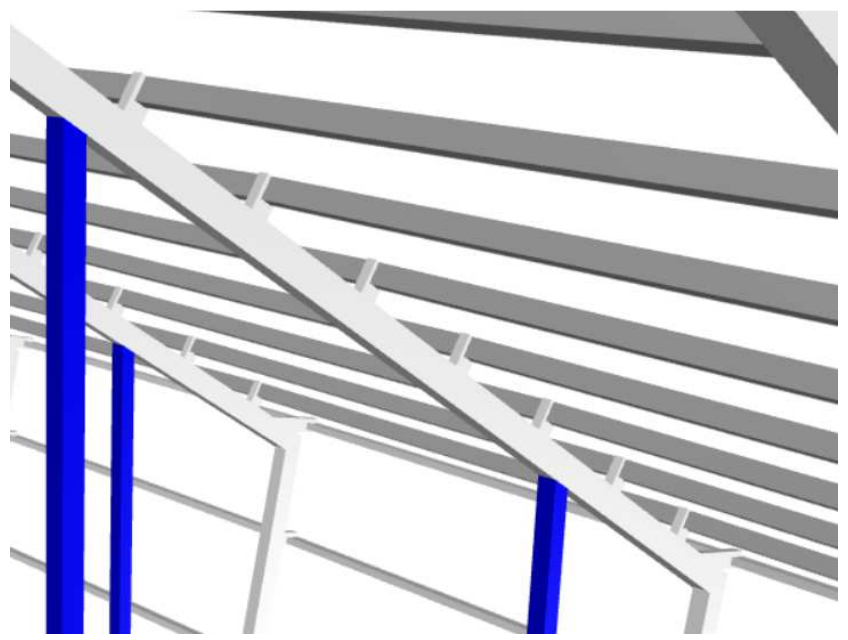

Figure 13. The transom is connected to the corbel of Vertical keel.

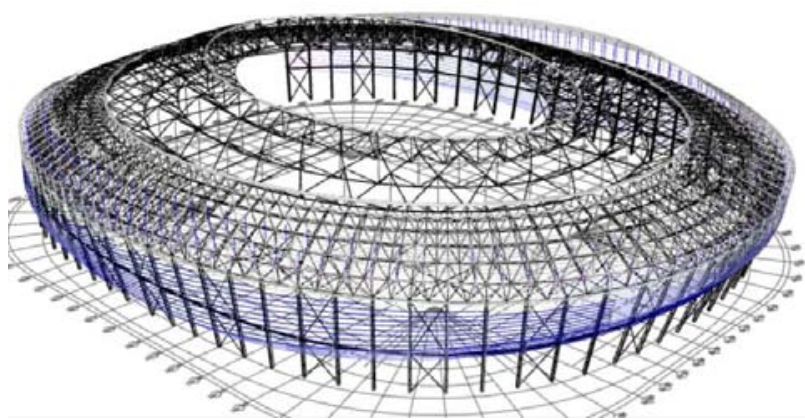

Figure 14. Installation simulation of steel mullion 1.

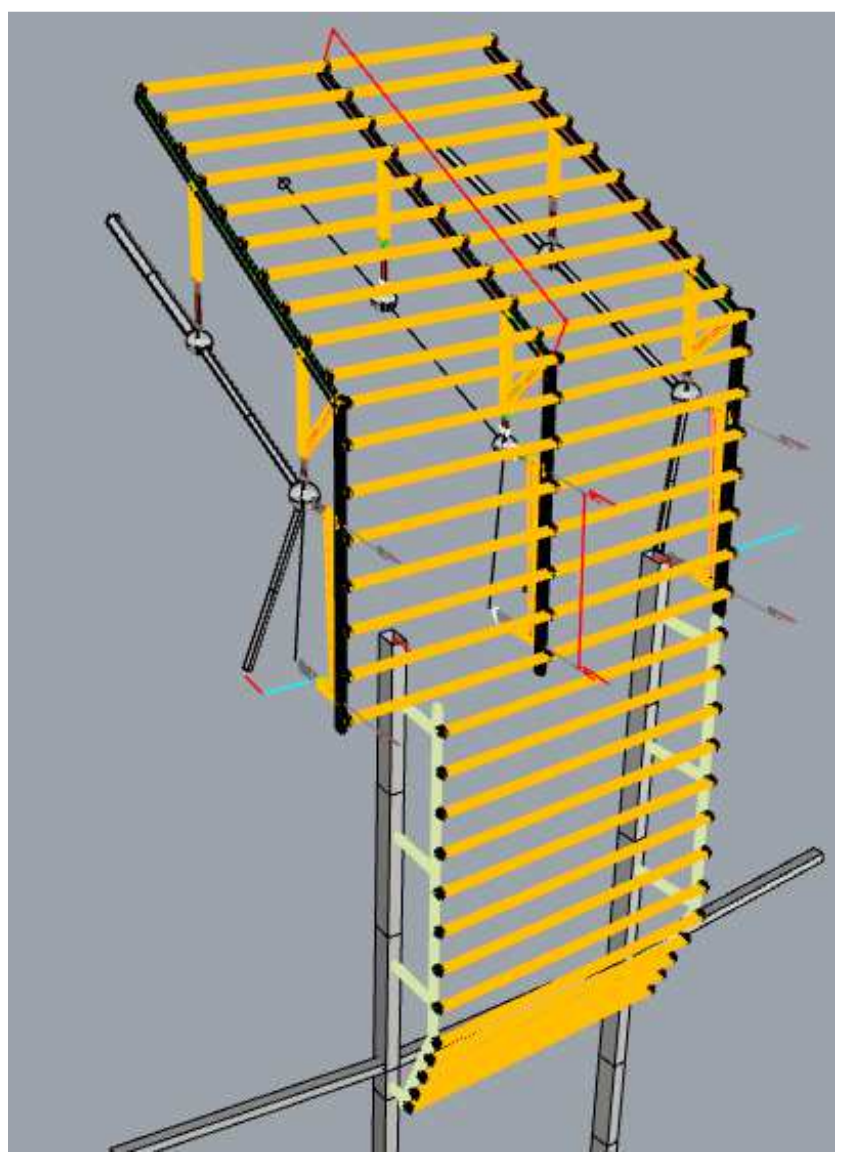

Figure 15. Installation simulation of steel mullion 2.

Steel square tube $300 \times 200 \times 12 \mathrm{~mm}$ ( $10 \mathrm{~mm}$ blocking plate at ends)

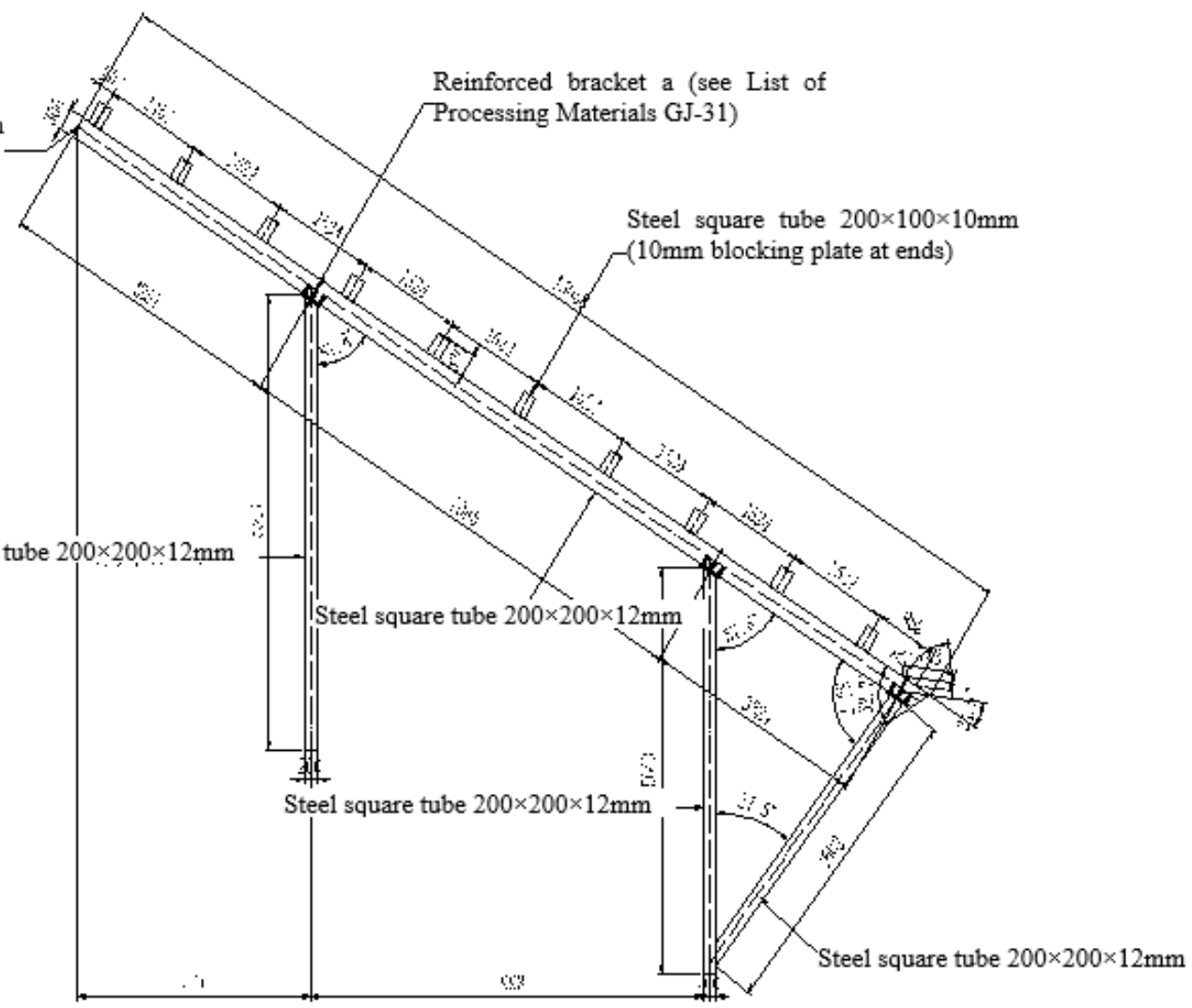

Figure 16. Welding installation 1. 


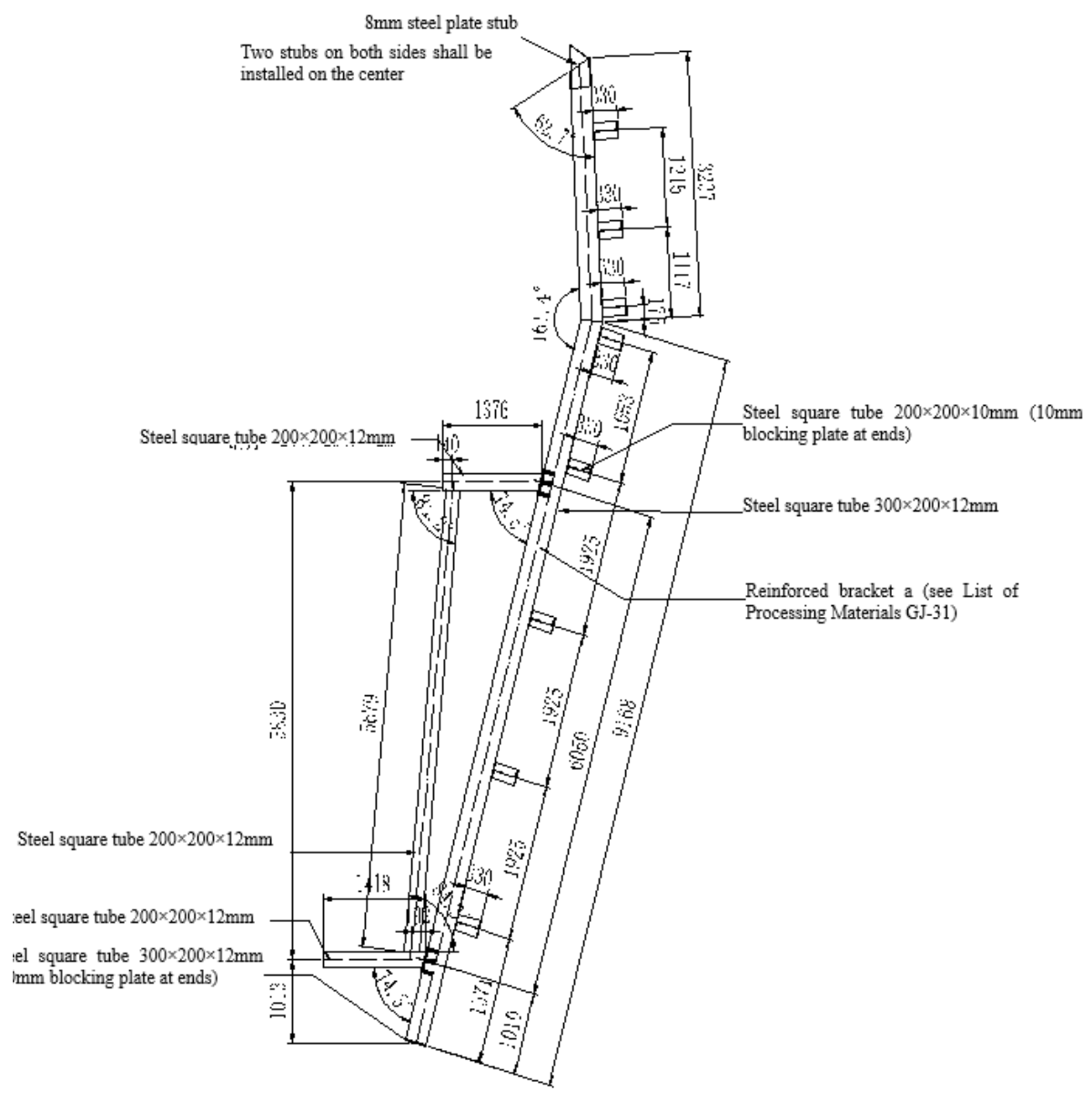

Figure 17. Welding installation 2.

\subsection{Severely Deformed Sectors Due to Complex Facade Shape}

The entire facade of the project is streamlined and irregular, the plane is elliptical, the upper and lower sides of the sector are curved and non-parallel, and the left and right sides are oblique (see the figure below), resulting in the inconsistent direction of the vertical and horizontal frames, which brings great challenges to the assembly of sectors

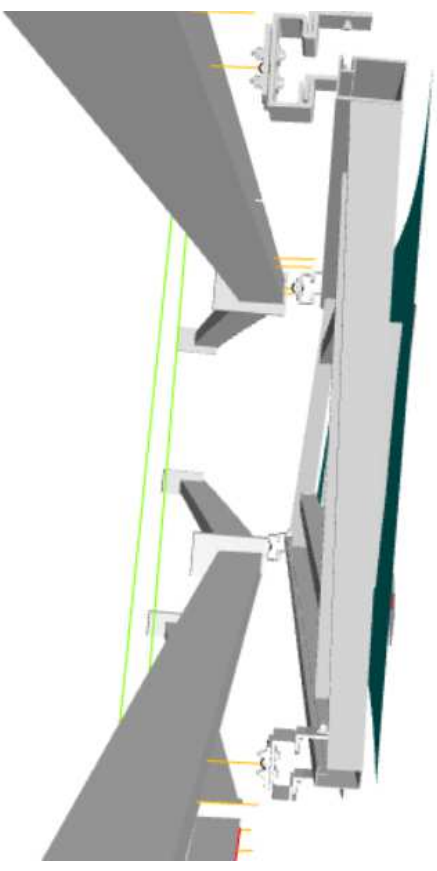

Figure 18. Sector deformation simulation. 
Based on the above reasons, our company puts the focus of the curtain wall system on absorption of positioning deviation and solution to the problem of sector deformation. The vertical section nodes for sector connection are as follows:

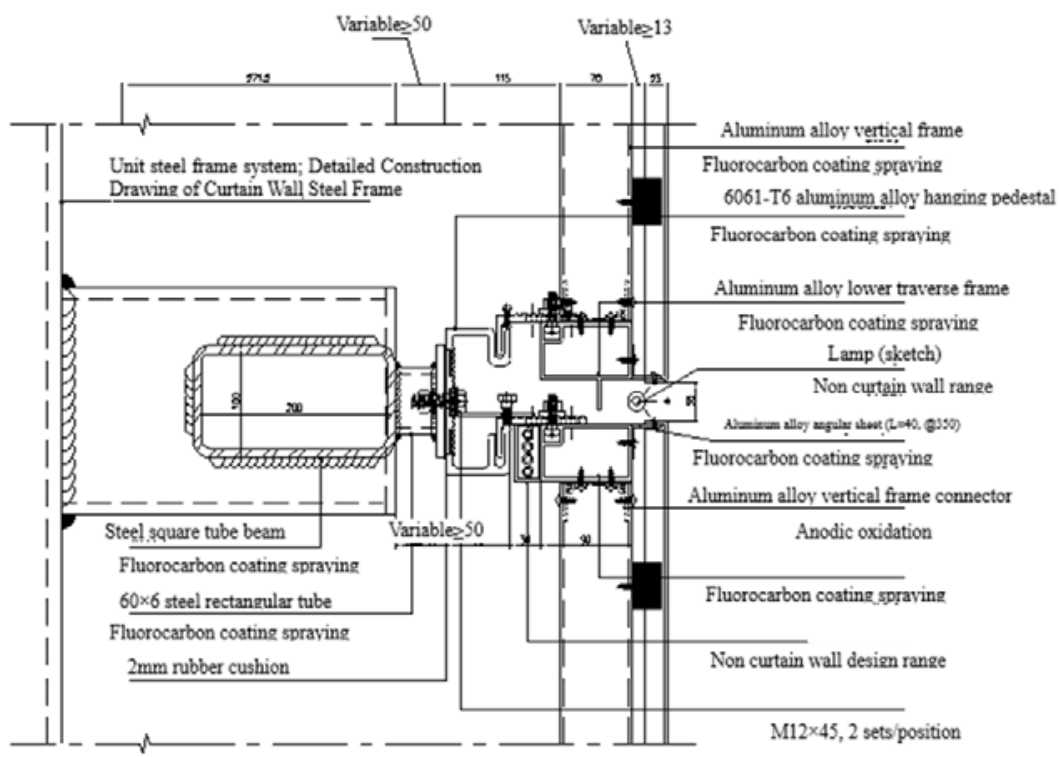

Figure 19. The vertical section nodes for sector connection.
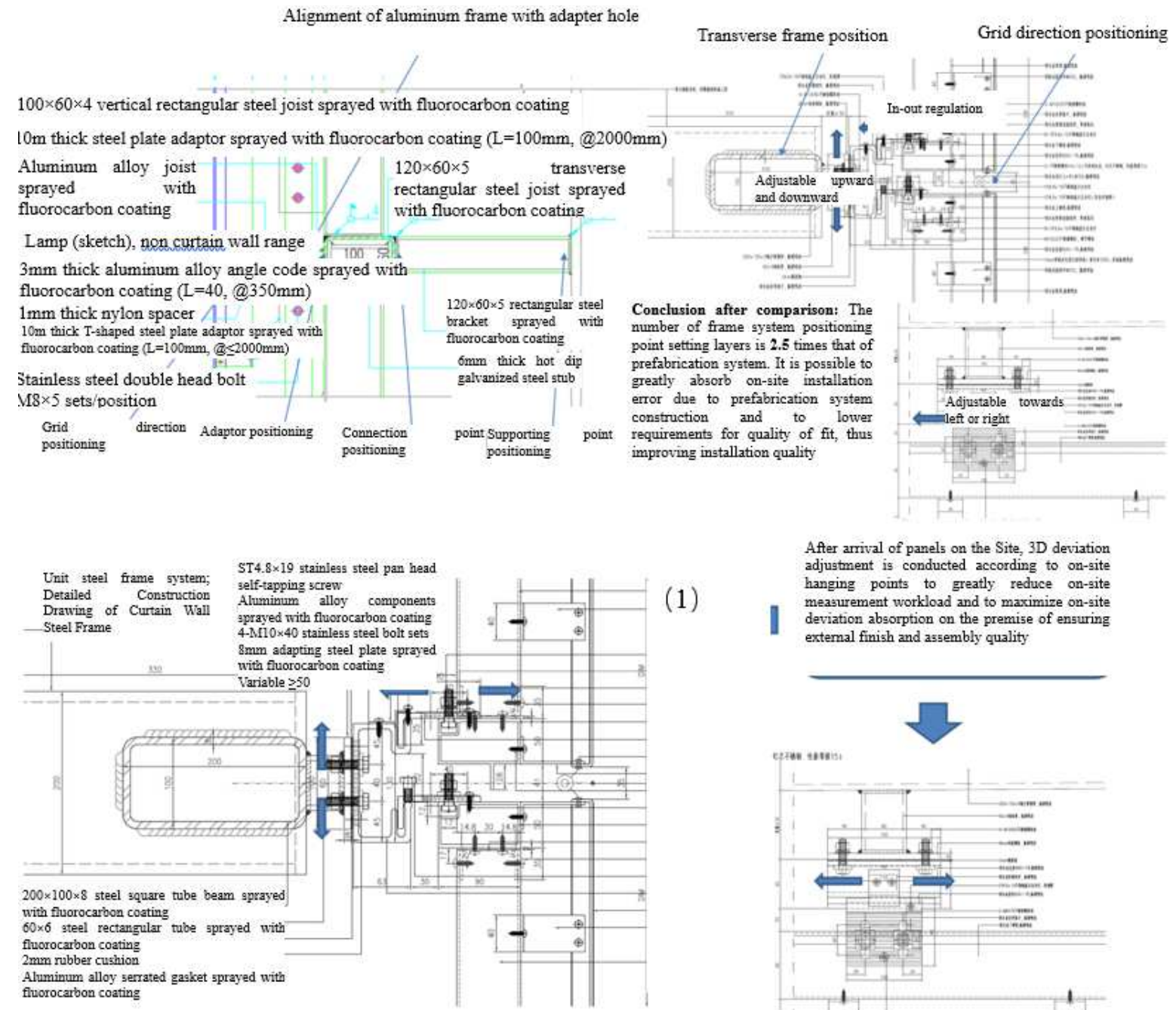

After arrival of panels on the Site, 3D deviation adjanting is conducted according to on-site hanging points to greatly reduce on-site measurem extemal finish and assembly quality

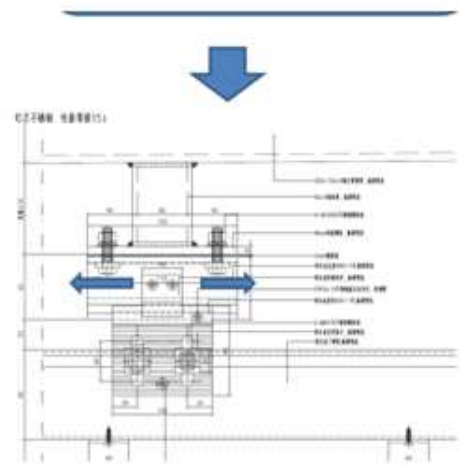




\begin{tabular}{|c|c|}
\hline (1) & 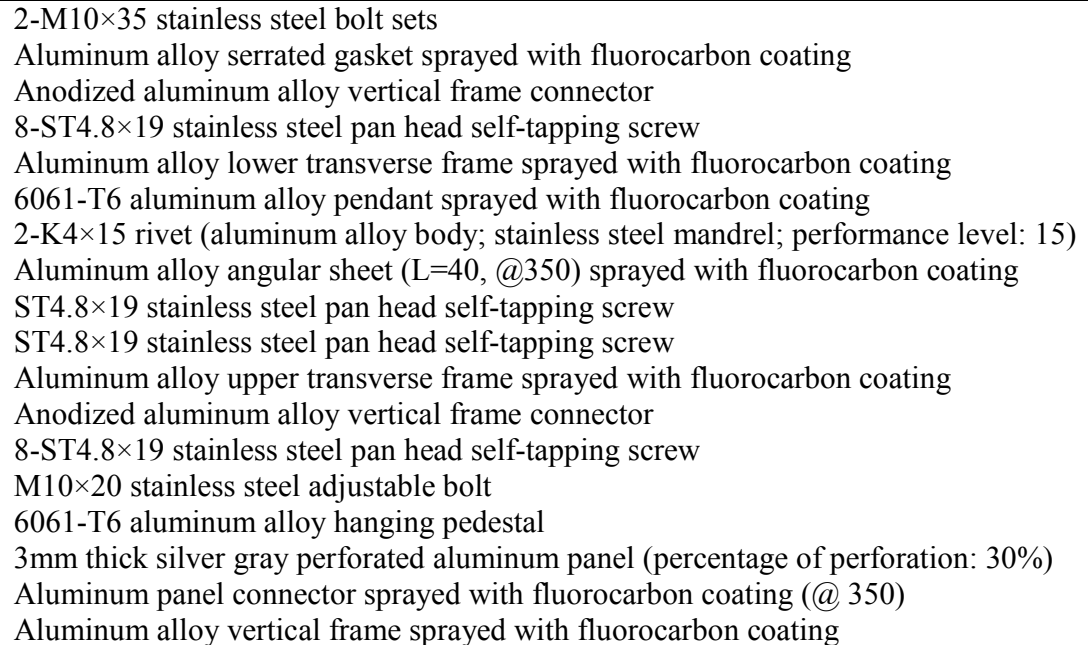 \\
\hline
\end{tabular}

Figure 20. Comparison of system structure before and after.

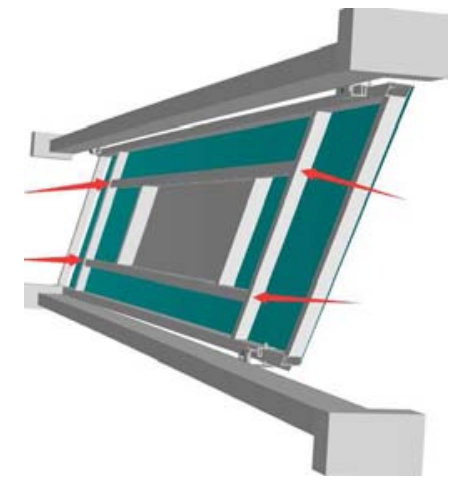

Figure 21. Junction of middle transom and mullion.

Through comparison, it is found that the modified system structure can effectively solve the problems of positioning and deviation absorption, and greatly relieve the pressure on on-site installation. At the same time, as mentioned above, sector deformation also affects the on-site installation. By analyzing the characteristics of sector deformation and spatial conditions, it is concluded that the torsion problem at the junction of the middle horizontal frame and vertical frame must be solved (see Figure 21). Otherwise, the sector will cause installation stress due to the change of its deformation amount [5].

The original horizontal frame corner piece connection scheme obviously cannot adapt to this deformation. The horizontal frame connection needs its own rotation angle and can maintain the integrity of the structure, so the node is modified as follows:

The horizontal frame insert core is modified into a circular arc structure, which achieves the purpose of positioning through the connection with the outer frame, and can absorb the internal stress generated by the rotation angle.

The upper and lower horizontal frame and the vertical frame are connected by strip aluminum components, which can ensure the basic limit torsion function of sectors, as shown in the figure below:

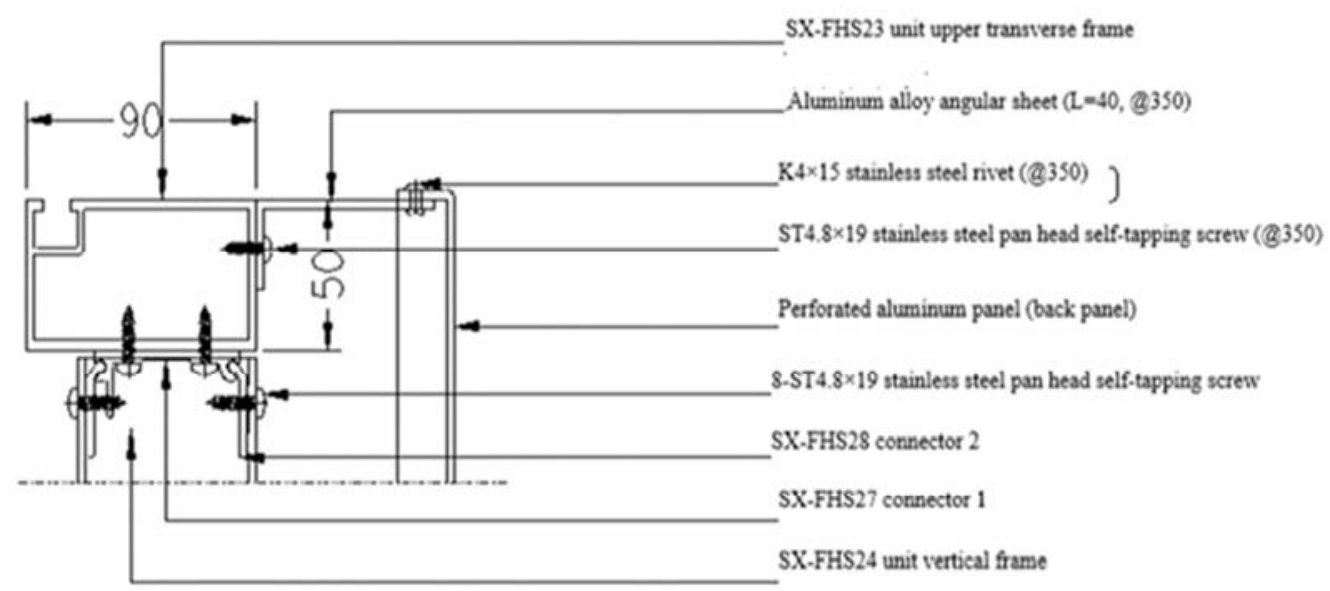

Figure 22. Node optimization.

After the above optimization steps, the overall sector is installed in the form of unit body weight hanging. On the premise of considering the ability to bear displacement and earthquake load, the sector can be adjusted and fine-tuned in three dimensions for moderate torsion. 


\subsection{Mass Sector Data}

The architectural skin of Phoenix Mountain Sports Center is complex and irregular. The whole is composed of 16 undulating spatial curved surfaces, and the curved surfaces grids are staggered and arranged with the spatial modeling. There are more than 5,500 curved plates with different shapes and sizes [6]. $80 \%$ of the sectors are unit frame by internal and external double-layer splicing, $20 \%$ of the sectors are unit frame by single-layer bottom panels, and the inner and outer layers are made of perforated aluminum panels of different specifications.

After the analysis of the skin shape (see Figure 24), the overall sector size and design plan, due to the large sector size, it is difficult to ensure the appearance and sector strength during processing and installation, so it is necessary to further divide the aluminum panels within a sector into grids [7]. The bottom back panels of the sector are divided into grids densely spliced by two on the left, two on the upper middle part, two on the lower middle, and two on the right, to connect the outer floating board. Based on different sizes of outer floating boards, we have classified sectors as follows:

1. When the outer floating board is less than $1600 \mathrm{~m}$ long, back panels on the upper middle and lower middle as well as aluminum panels are combined into an aluminum panel.

2. When the outer floating board is more than $2000 \mathrm{~mm}$ long, vertical frame is incorporated into floating board frames for reinforcement.

3. It shall be ensured that bottom back panels at both sides are not greater than $1000 \mathrm{~mm}$ long. If greater than $1000 \mathrm{~mm}$ long, it is necessary to add more grids for dense splicing.

4. Grids for dense splicing shall be formed on the premise that the side length of the non-floating board is no more than $1200 \mathrm{~mm}$.

5. Suspended edges at the junction of curved surfaces shall be subject to unit group frame as per designed size requirements.

After confirmation of grid division scheme, we start to consider optimization of panels and group frames. Because the diving plane is a double curved surface with spatial freedom, the corresponding double curved profiles are characterized by high processing difficulty, high cost and long cycle. Thus, we begin with optimization of aluminum profiles for group frame, namely optimization of two traverse profiles. Since the two traverse profiles must ensure direction of curved surfaces for good appearance effects and connection angle with panels, the conventional method of three-point fitting for arc building cannot effectively control the connection angle of aluminum profiles with panels, however, and the method of projection for arc building without arc rise may result in deviation of $0 \mathrm{~mm}-200 \mathrm{~mm}$ of group frame angular point. By calculation, we finally adopt two methods for connection, through which we can ensure single curved arc, control profile direction (see Figures 24 and 29), and control group frame angular point. After confirmation of group frame, we focus on curved surface analysis and optimization [8]. Since curved surfaces are divided into grids and staggered, conventional methods of curved surface optimization fail to effectively solve angular point misalignment due to staggered joints. Finally, we decide to control angle code length by means of parameters to ensure that the angular points of each aluminum panel within a unit are attached to the original curved surface trend line, to achieve the effect of restoring curved surface shape by simulation.

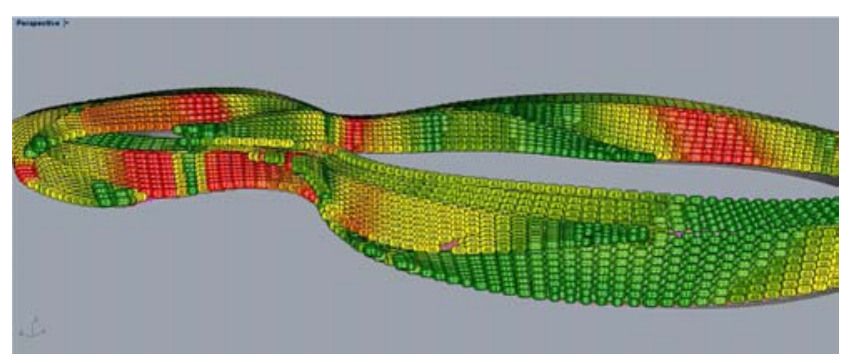

Figure 23. Analysis of the skin shape.

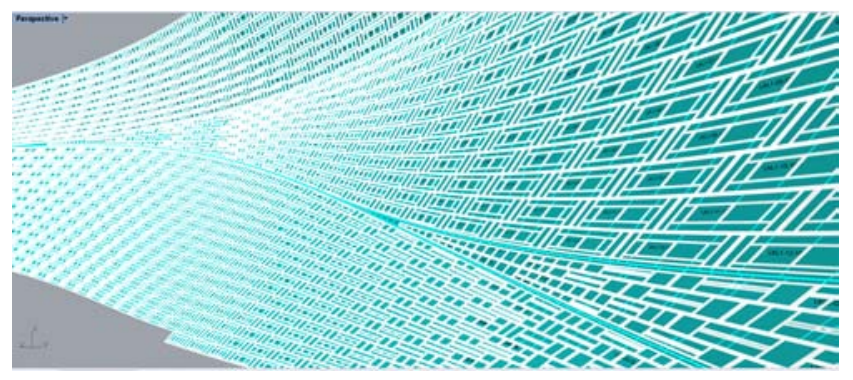

Figure 24. Aluminum plates.

Due to complexity and diversity of the project, we analyze the integral hoisting scheme and sector size characteristics, and finally classify more than 5500 double curved hoisted units of different sizes and shapes into 10 kinds of different panel splicing schemes, 2 kinds of panel materials, 37 kinds of unit group frame and 6 kinds of profile section. There is a total of more than 50000 aluminum panels and corresponding 50000 profiles with different shapes.

Due to too many types of units to be hoisted in this Project, modeling and data processing in a convention way will bring heavy workload and irregular group frame distribution will generate chaotic data. Hence, we do not handle it by conventional classification, but perform programming in two types as per project characteristics. We classify splicing of 4 kinds of aluminum panels in a sector with floating boards as one type, and splicing of 6 kinds of aluminum panels in a sector without floating boards as the other. Then the group frame will generate naturally. This method can not only improve work efficiency, but also ensure regularity of later-stage data to a maximum extent. We perform programming with such a idea by setting different trigger conditions in the program (see Figure 26) to automatically generate different types of sectors and group frame models according to trigger and to generate sector number and model through one click (see Figures 27-29). 


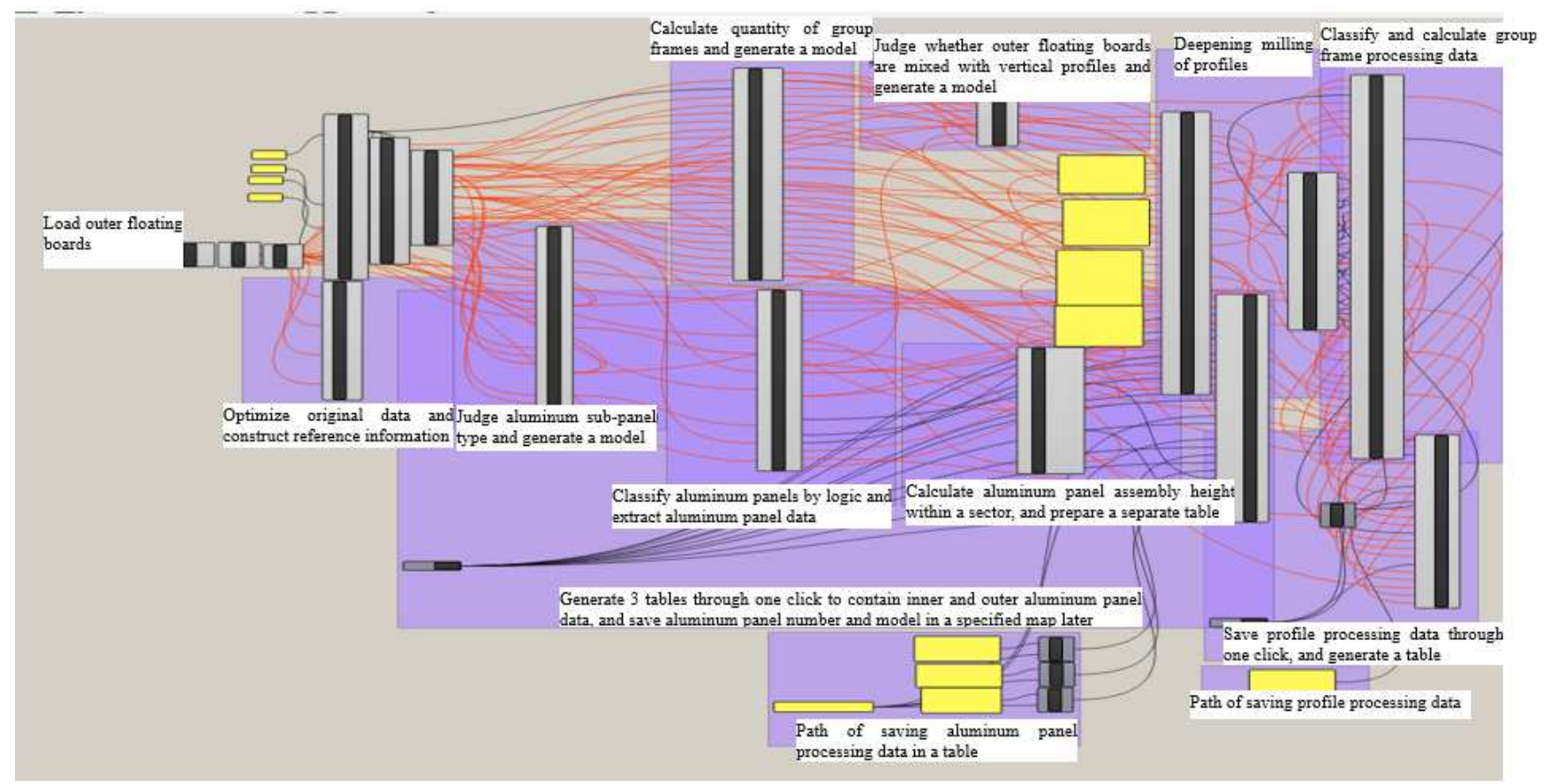

Figure 25. Different trigger conditions in the program.

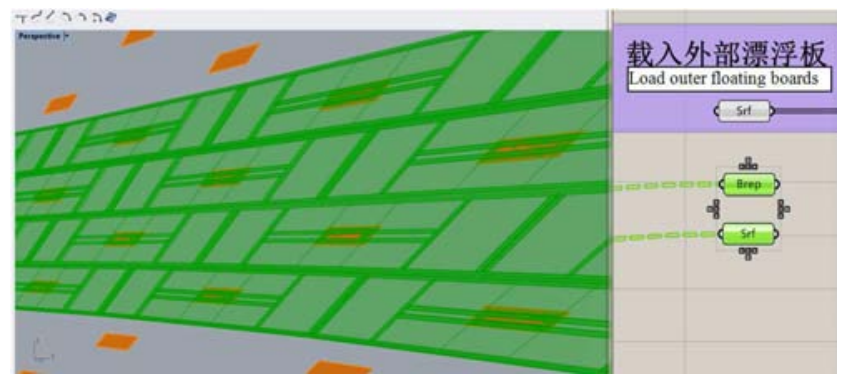

Figure 26. Curtain wall plates model.

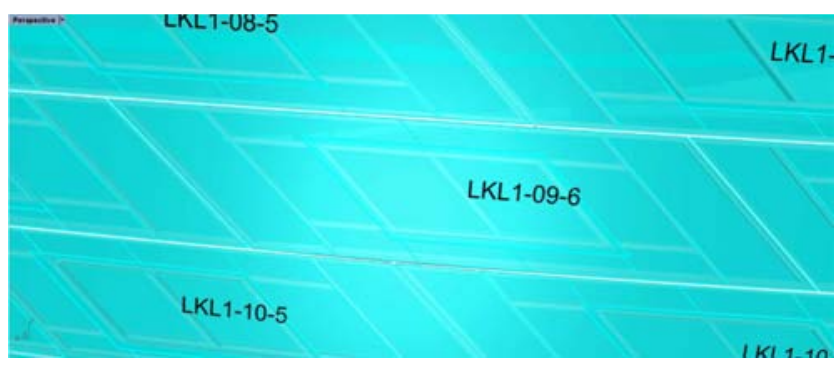

Figure 27. Number of curtain wall plates (1).

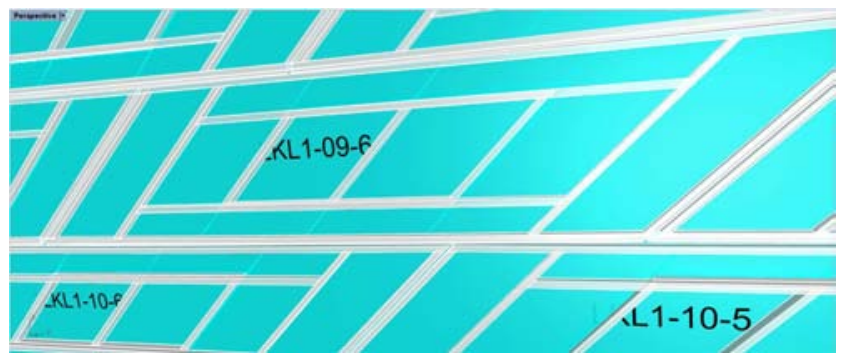

Figure 28. Number of curtain wall plates (2).
We need to process mass data in this Project, including the quantity of each kind of aluminum panels for each unit to be hoisted, processing data, relative position relation of splicing, profile quantity, milling shortage angle of each profile, curved arc radius, curved arc direction, pore position, relative position of profile installation, etc.

Based on previous classification, we only need to set the order inside the sector when processing data: the order of aluminum panels in each sector are arranged from left to right and from up to down, while group frames are arranged from up, down to left and right based on installation position [9]. We tabulate aluminum panel and group frame data, respectively, and arrange them in an equivalent manner in the table. In an equivalent tabulated frame, supposing that we set 13 profile positions and 10 fixed hole positions, and reflect number change in the designated location in the table. For example, if vertical frame in the floating board is not required, "/" will be entered in corresponding hole position and vertical frame processing parameter (see Figures 30 and 31). After such processing, we may ignore problems such as quantity and splicing of different kinds of aluminum panels and group frames [10]. Even if we put sectors with different group frame types in one table, we can still clearly identify group frame type, sector form and other processing parameters from the generated EXCEL form only if we know table layout logic rules [11]. We can effectively mitigate complexity of processing, assembly and on-site disclosure caused by diversified sector types, diversity of data re-processing in later period, and other problems. A tabulated working diagram expressed in parameters can simplify complex issues and greatly improve efficiency [12]. 


\begin{tabular}{|c|c|c|c|c|c|c|c|c|c|c|c|c|}
\hline 85 & LKL3-08-7 5853.311 & 5942.731 & 1673.77 & 1824.468 & 7161.143 & 4939.888 & 1028.481 & 1017.056 & 1031.75 & 1043.518 & / & $/$ \\
\hline 86 & LKL3-08-7 5895.455 & 5853.327 & 42.12812 & 49.99 & 130.11 & $/$ & $/$ & 6.147605 & 706705 & & & \\
\hline 87 & LKL3-08-7 6011.504 & 5943.045 & 68.45856 & 48.78 & 131.27 & $/$ & $/$ & 5.742002 & 786705.9 & & & \\
\hline 88 & LKL3-08-7 3821.467 & $/$ & $/$ & 49.58 & 130.24 & $/$ & $/$ & $/$ & $/$ & & & \\
\hline 89 & LKL3-08-7 3818.062 & / & $/$ & 49.58 & 130.24 & $/$ & $/$ & $/$ & $/$ & & & \\
\hline 90 & LKL3-08-7 1583.189 & / & $/$ & 130.02 & 48.78 & 89.4 & 90.01 & $/$ & / & & & \\
\hline 91 & LKL3-08-7 1732.046 & $/$ & $/$ & 130.11 & 48.74 & 89.98 & 89.39 & $/$ & $/$ & & & \\
\hline 92 & LKL3-08-7 1600.209 & 406.1255 & 827.4546 & 129.68 & 49.13 & 89.51 & 89.9 & $/$ & $/$ & & & \\
\hline 93 & LKL3-08-7 1699.428 & 413.5743 & 825.2513 & 129.81 & 49.03 & 89.88 & 89.5 & $/$ & $/$ & & & \\
\hline 94 & LKL3-08-7 1747.269 & $/$ & $/$ & 25 & 65 & $/$ & $/$ & $/$ & $/$ & & & \\
\hline 95 & LKL3-08-7 1747.269 & $/$ & $/$ & 115 & 155 & $/$ & $/$ & $/$ & $/$ & & & \\
\hline 96 & LKL3-08-7 887.7923 & $\gamma$ & $/$ & 155 & 115 & 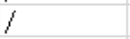 & $/$ & $/$ & $/$ & & & \\
\hline 97 & LKL3-08-7 887.7893 & $/$ & $/$ & 65 & 25 & $/$ & $/$ & $/$ & $/$ & & & \\
\hline 98 & LKL $3-08-7-13$ & / & / & & & / & / & $/$ & $/$ & & & \\
\hline 99 & LKL3-08-8 5854.961 & 5937.861 & 1825.38 & 1966. 784 & 7277.003 & 4874.824 & 980.6343 & 966.1311 & 978.8132 & 993.6026 & 906.4054 & 906.4053 \\
\hline 100 & LKL $3-08-\varepsilon 5897.352$ & 5854.982 & 42.37037 & 49.88 & 130.28 & $/$ & $/$ & 6.843043 & 635293.1 & & & \\
\hline 101 & LKL $3-08-\varepsilon 6006.821$ & 5938.151 & 68.6691 & 48.73 & 131.36 & $/$ & $/$ & 6.158133 & 732402.3 & & & \\
\hline 102 & LKL3-08-8 3921.045 & $/$ & $/$ & 49.53 & 130.29 & $/$ & $/$ & $/$ & $/$ & & & \\
\hline 103 & LKL $3-08-\varepsilon 3917.118$ & $/$ & $/$ & 49.53 & 130.29 & $/$ & $/$ & $/$ & $/$ & & & \\
\hline 104 & LKL3-08-8 1734.711 & $/$ & $/$ & 130.12 & 48.73 & 89.46 & 89.98 & $/$ & $/$ & & & \\
\hline 105 & LKL $3-08-\varepsilon 1874.355$ & $/$ & $/$ & 130.27 & 48.65 & 89.97 & 89.44 & $/$ & $/$ & & & \\
\hline 106 & LKL $3-08-\varepsilon 1746.873$ & 413.1136 & 959.5277 & 129.74 & 49.13 & 89.55 & 89.89 & $/$ & $/$ & & & \\
\hline 107 & LKL3-08-8 1842.669 & 419.036 & 956.9849 & 129.91 & 49 & 89.88 & 89.53 & $/$ & $/$ & & & \\
\hline 108 & LKL $3-08-\varepsilon 1947.269$ & $/$ & $/$ & 25 & 65 & $/$ & / & $/$ & $/$ & & & \\
\hline 109 & LKL $3-08-\varepsilon 1947.269$ & $/$ & $/$ & 115 & 155 & $/$ & $/$ & $/$ & $/$ & & & \\
\hline 110 & LKL3-08-8 1018.329 & $/$ & $/$ & 155 & 115 & $/$ & $/$ & $/$ & $/$ & & & \\
\hline 111 & LKL $3-08-\varepsilon 1018.352$ & 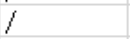 & / & 65 & 25 & $/$ & 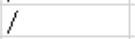 & $/$ & / & & & \\
\hline 112 & LKL3-08-8 929. 6434 & $/$ & / & 130 & 50 & $/$ & $/$ & $/$ & $/$ & & & \\
\hline
\end{tabular}

Figure 29. Processing parameters (1).

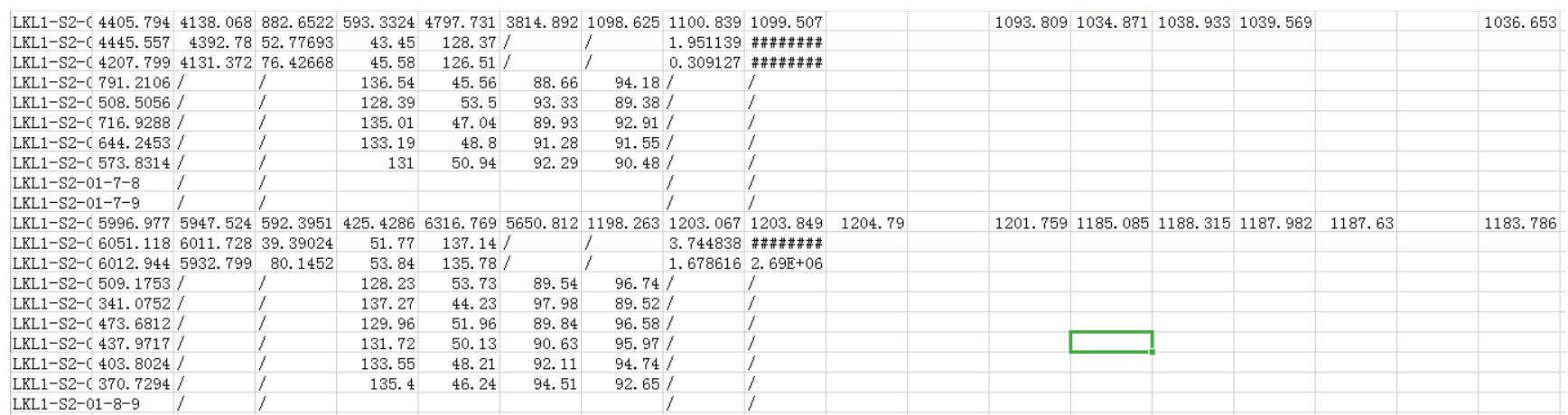

Figure 30. Processing parameters (2).

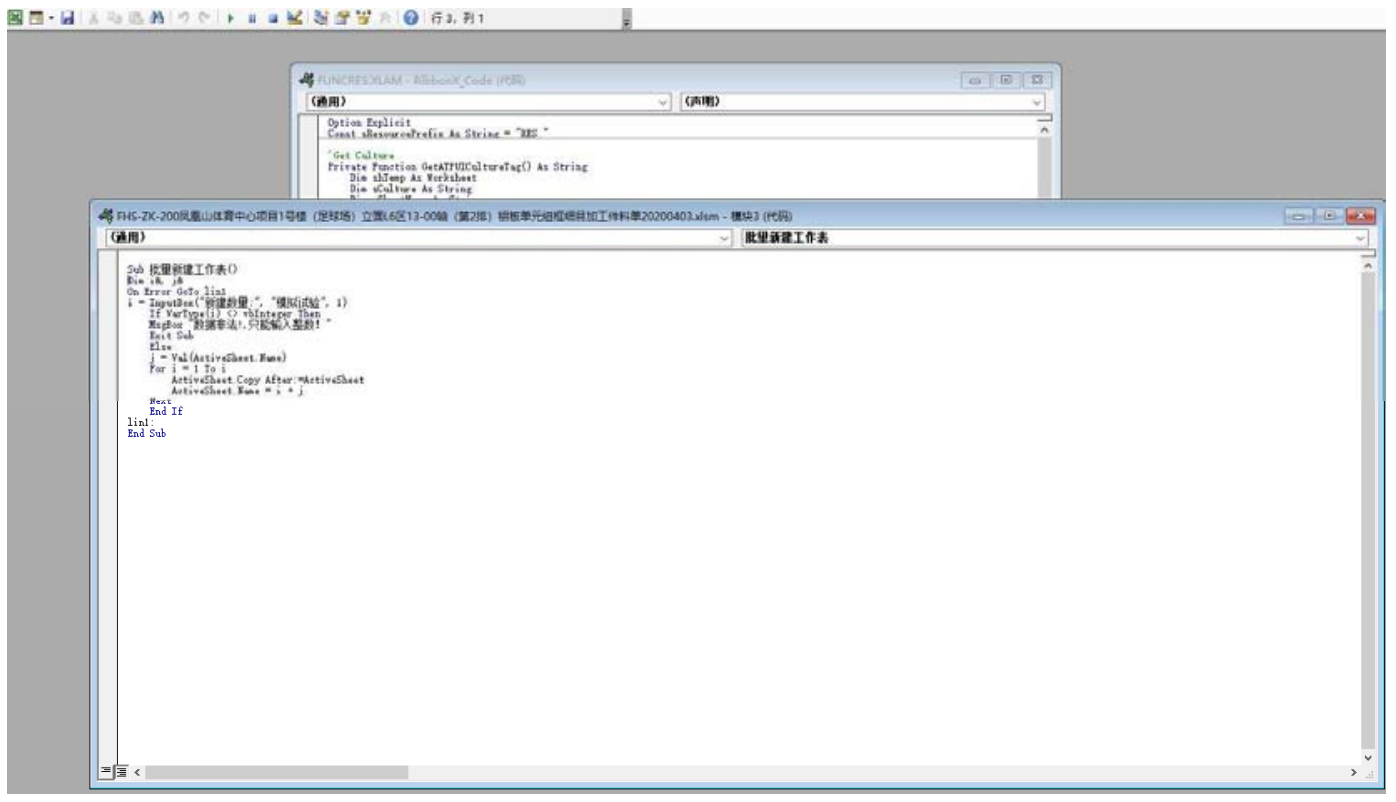

Figure 31. Small bulk tools. 
Similarly, when we complete programming, we only need to simply adjust sector starting and ending numbers and enter parameters to ensure one-click bulk output of models and data.

\subsection{Tedious Data Processing}

Data processing and application have always been applicable to blanking procedures of the construction organization. Traditionally, data use basically refers to copying and pasting a form and based on which a BOM is prepared that is suitable to the company [13]. Since mass data in this Project, it is required to continuously improve efficiency of staff and BIM supporting nature. Otherwise, BIM work will not be extended and utilized. To this end, our company programs a BOM matching the Project with EXCEL table functions and macro command (Figure 32) according to data format and the basic tables, completes bulk table data index (Figure 34) with prepared basic information using small bulk tools (Figure 33). According to calculation results based on actual work effects, this measure has saved design costs of 2-3 labor, greatly shortened work hours, improved staff efficiency, improved BIM interface matching degree, and provided desirable experience for design coordination of other projects [14].

\section{Scheme Application Effect}

The theoretical scheme shall be tested by practice [15]. Two tests with visual sample panels and one test with real sample panels have fully demonstrated the feasibility of the scheme.

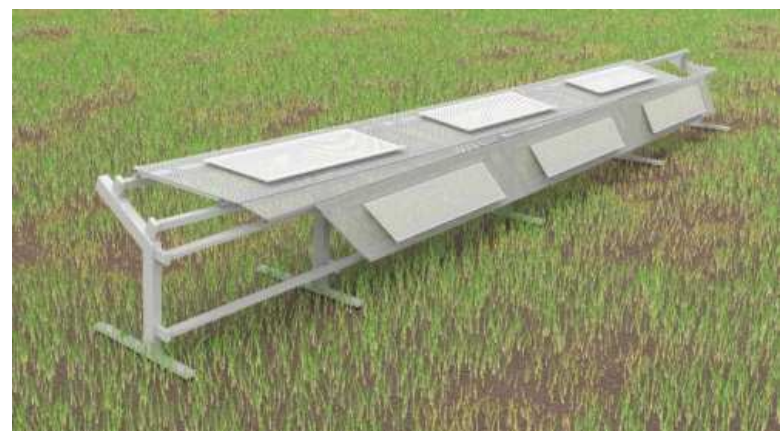

Figure 32. Effect picture of visual sample panels.

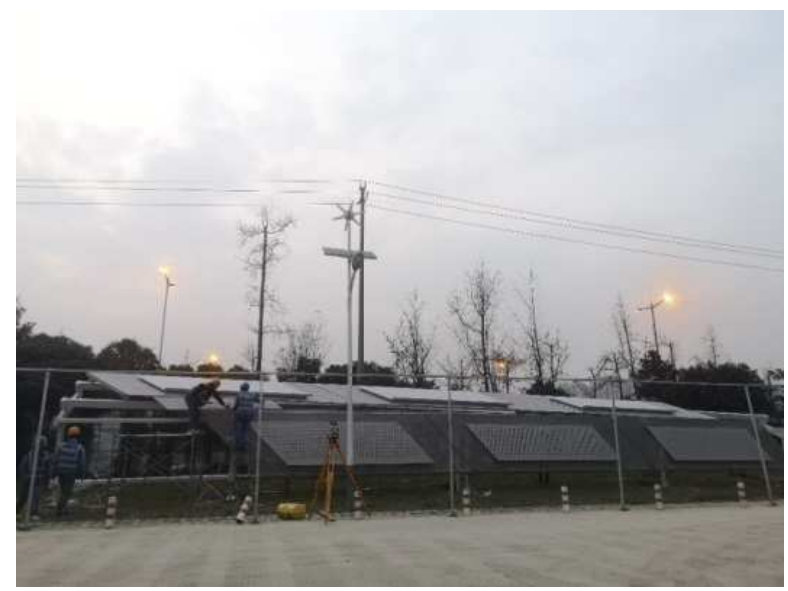

Figure 33. On-site installation of visual sample panels.

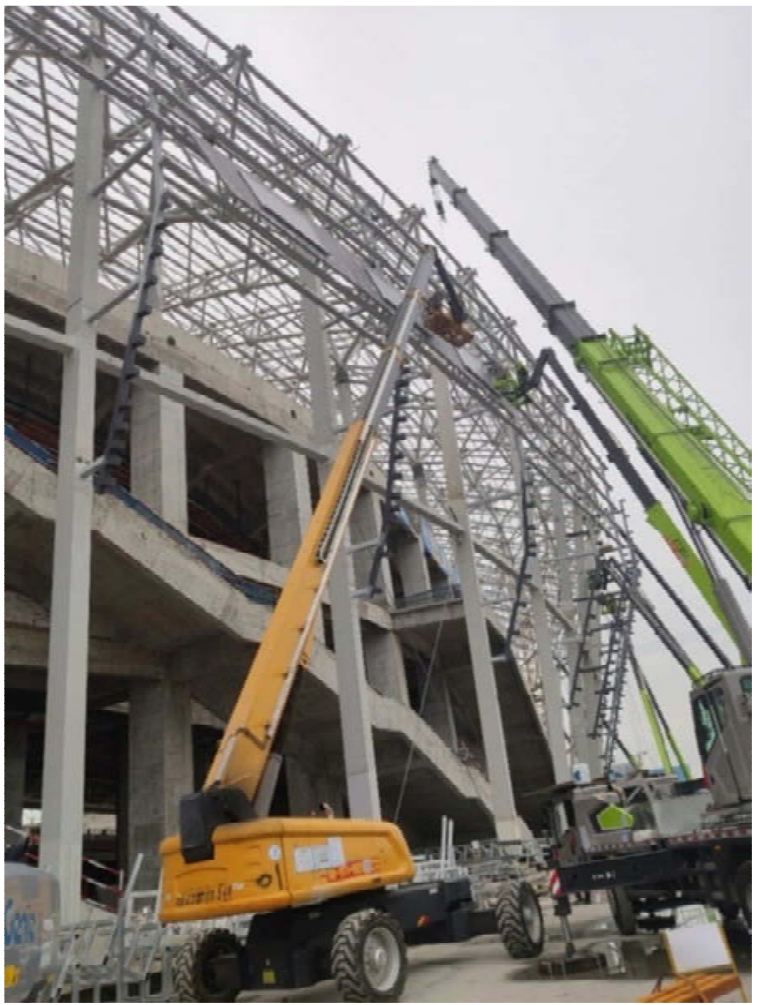

Figure 34. Hoisting of real sample panels for on-site installation.

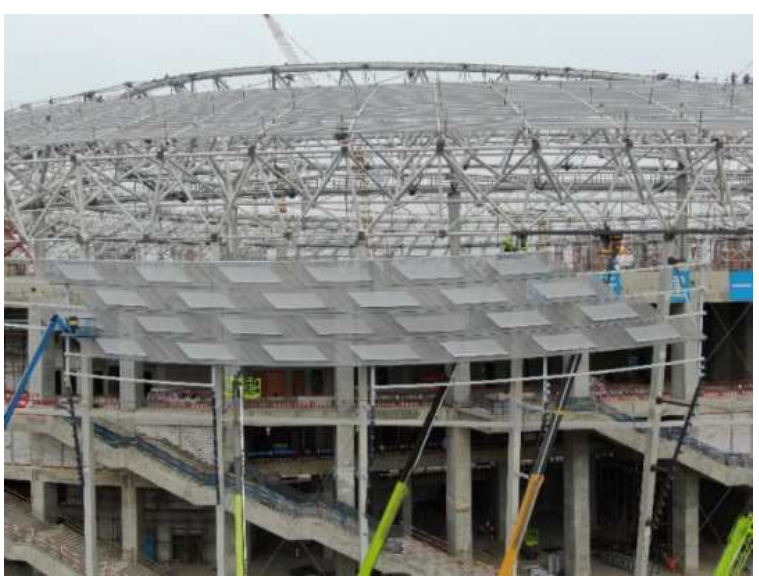

Figure 35. Installation adjustment of real sample panels.

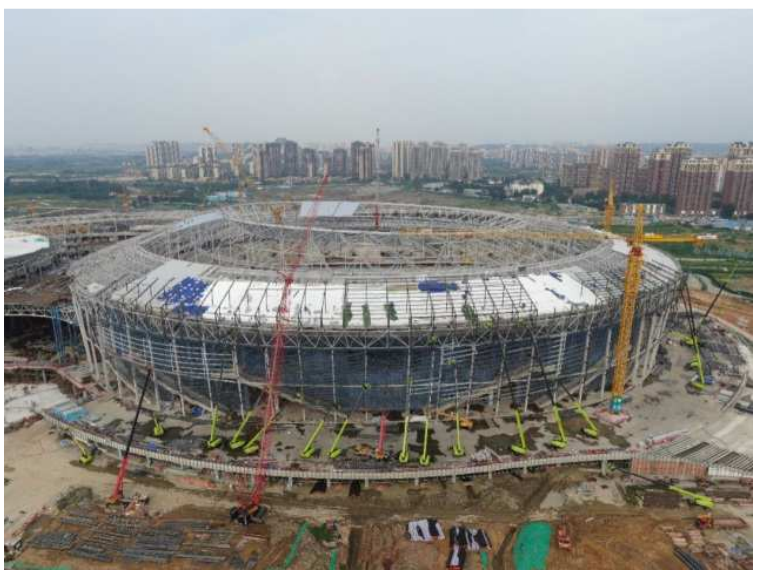

Figure 36. Construction site in full swing 


\section{Summary}

The Project is under orderly progress and various materials are delivered to the Site through concerted efforts of the Project Team. A series of practices have proven that a large stadium can be constructed according to the integral hoisting scheme of sectors. Studies on how to design overall hoisting system for steel joist of large volume unit, how to install the steel joist of large volume unit, how to install non-coplanar special-shaped curtain wall and how to implement integral hoisting of metal roofing purlin may help to solve difficulties such as difficult construction, high cost and uncontrollable quality of large volume non-coplanar special-shaped curtain wall. Especially, studies on prefabrication construction techniques may help to simplify complex traditional bulk construction procedures, save time, improve work efficiency and reduce construction costs.

\section{References}

[1] Prefab Architecture: A Guide to Modular Design and Construction. Ryan E Smith. Wiley Series in Solution Chemistry. 2010.

[2] Design Concept and Key Construction Technology of Extra-Large Unit-Type Curtain Wall [J]. Lv Wei, Sun xulie, Ji Pengcheng. Construction Technology. 2018 (S1).

[3] Discussion on Design of Special-Shaped Unit-Type Curtain Wall in Prefabricated Building [J]. Zeng Weiqing, Yu Guobao. Building Technology. 2018 (03).

[4] Pressure equalization performance of a metal and glass curtain wall. Ganguli U, Quirouette RL. CSCE Centennial Conference. 1987.

[5] Principles of Curtain Walling. Kawneer UK Limited.. 1999.

[6] Design of flexiblehanging curtain wall support structure. DING J M, LI J P, HE Z J, et al. The CTBUH9th World Congress. 2012.

[7] Risk Management in Construction Projects: A Knowledge-based Approach [J]. Alfredo Federico Serpella, Ximena Ferrada, Rodolfo Howard, Larissa Rubio. Procedia Social and Behavioral Sciences. 2014.

[8] Large engineering project risk management using a Bayesian belief network [J]. Eunchang Lee, Yongtae Park, Jong Gye Shin. Expert Systems With Applications. 2008 (3).

[9] Structural System and Detail Design of Unit-Type Curtain Walls [J]. Fang Jin. Building Construction. 2008 (10).

[10] Structural characterisation of textile ceramic technology used as a curtain wall $[\mathrm{J}]$. Ernest Bernat-Maso, Lluis Gil, Pere Roca, Vicen? Sarrablo, Christian Escrig. Engineering Structures. 2013.
[11] Optimisation of curtain wall faades for office buildings by means of PSO algorithm [J]. Gianluca Rapone, Onorio Saro. Energy \& Buildings. 2011.

[12] Comparative assessment of life cycle impacts of curtain wall mullions [J]. Rahman Azari-N, Yong-Woo Kim. Building and Environment. 2011.

[13] Construction of Irregular Curtain Walls [J]. Zhou Hong, Liu Zhiyong, Tang Weidong, Yuan Mingliang, Fei Jianfeng. Building Construction. 2006 (11).

[14] Song, J. H.; Lim, J. H.; Song, S. Y. Evaluation of alternatives for reducing thermal bridges in metal panel curtain wall systems [j] Energy Build., 2016.

[15] Construction of New Steel-cable Point-supported Curtain Walls [J]. Cao Xinghua. Building Construction. 2005 (01).

\section{Biography}

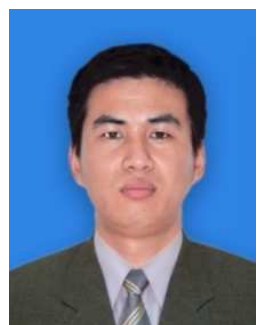

Xiong Wei: He is Design Chief (in Curtain Wall) of China Construction Shenzhen Decoration Co., Ltd., ever participated in several special-shaped complex projects, and is good at solving difficult problems and designing various types of systems. He serves as Design Leader in this Project.

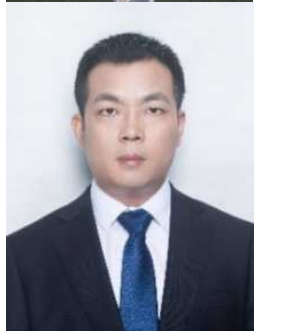

Gong Wang: He is Design Chief (in Curtain Wall) of China Construction Shenzhen Decoration Co., Ltd., has been engaged in curtain wall design for a decade, and ever participated in multiple domestic difficult special-shaped projects. He serves as Person in Charge of Scheme in this Project

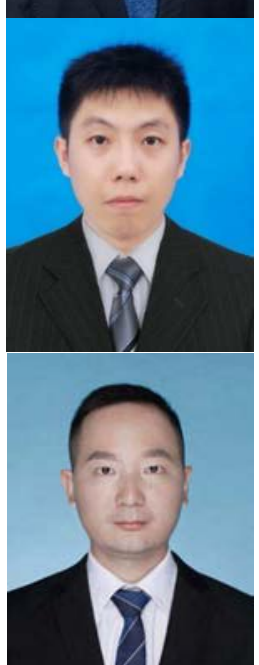

Liu Chang: He is (Curtain Wall) Designer of China Construction Shenzhen Decoration Co., Ltd., and has been engaged in curtain wall design for five years. He is responsible for detailed design in this Project

Ma Yong: $\mathrm{He}$ is BIM Design Chief (in Curtain Wall) of China Construction Shenzhen Decoration Co., Ltd., has been engaged in BIM for five years, and ever participated in multiple domestic difficult special-shaped projects. He serves as Person in Charge of BIM in this Project. 